\title{
Article
}

\section{Using a Structured Model to Promote Mental Health}

Keeling, Joanne and McQuarrie, Catherine

Available at http://clok.uclan.ac.uk/23335/

Keeling, Joanne ORCID: 0000-0002-0151-7234 and McQuarrie, Catherine (2018) Using a Structured Model to Promote Mental Health. Journal of Public Mental Health, 17 (3). pp. 114-121. ISSN 1746-5729

It is advisable to refer to the publisher's version if you intend to cite from the work. http://dx.doi.org/10.1108/JPMH-12-2017-0040

For more information about UCLan's research in this area go to http://www.uclan.ac.uk/researchgroups/ and search for <name of research Group>.

For information about Research generally at UCLan please go to http://www.uclan.ac.uk/research/

All outputs in CLoK are protected by Intellectual Property Rights law, including Copyright law. Copyright, IPR and Moral Rights for the works on this site are retained by the individual authors and/or other copyright owners. Terms and conditions for use of this material are defined in the policies page.

\section{CLoK}

Central Lancashire online Knowledge www.clok.uclan.ac.uk

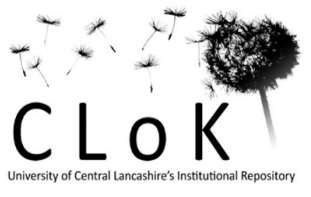




\section{Using a Structured Model to Promote Mental Health}

\begin{tabular}{|r|l|}
\hline Journal: & Journal of Public Mental Health \\
\hline Manuscript ID & JPMH-12-2017-0040.R1 \\
\hline Manuscript Type: & Original Research Paper \\
\hline Keywords: & $\begin{array}{l}\text { Therapeutic relationship, Holistic approach, Creativity, Mental Health } \\
\text { Promotion }\end{array}$ \\
\hline \multicolumn{2}{|l}{} \\
\hline
\end{tabular}

SCHOLARONE ${ }^{\text {m }}$

Manuscripts 


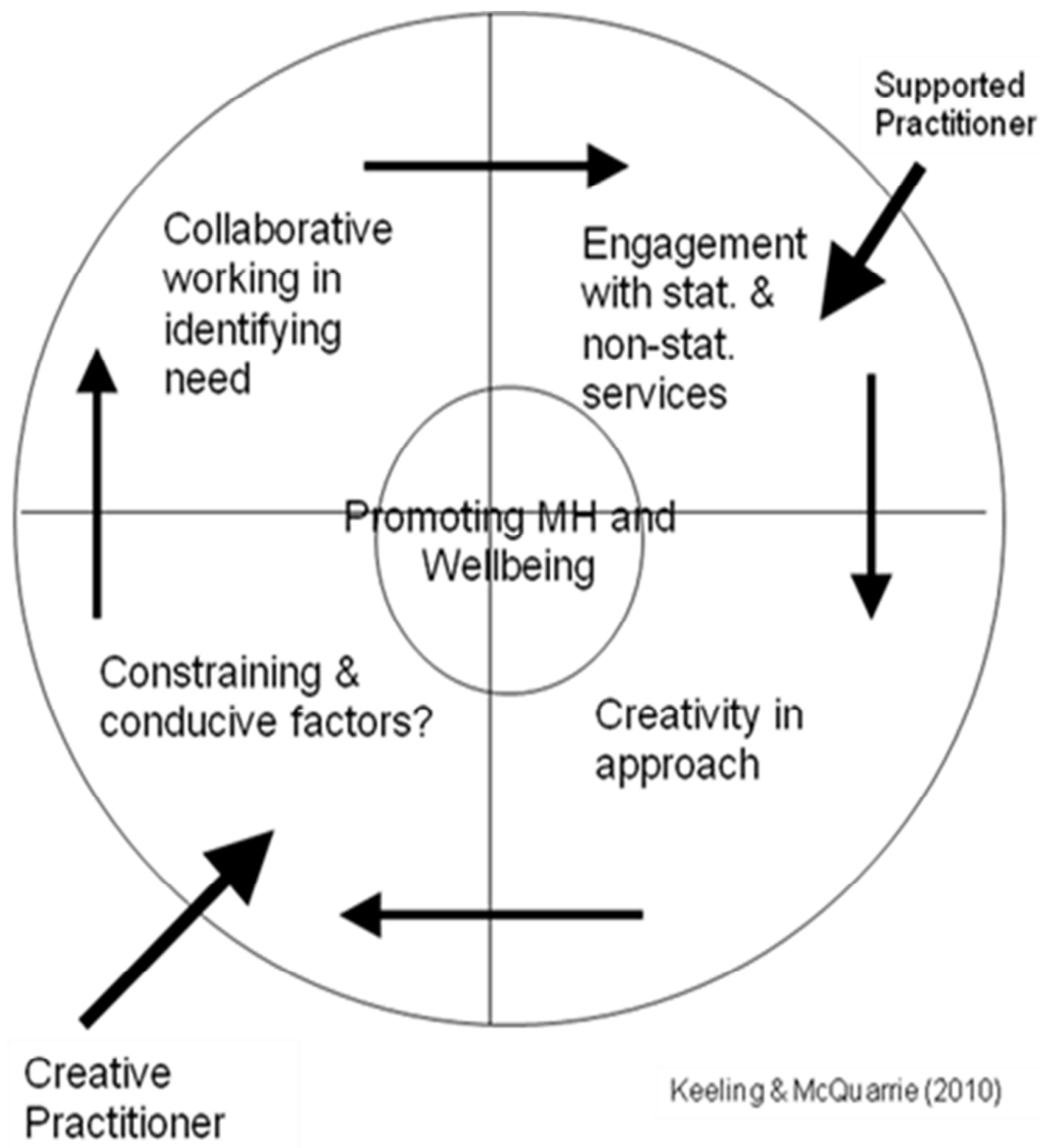

Figure 1.

Promoting Mental Health andWellbeing in Practice - A Working Model. 
Figure ii.

Table of themes and illustrative data extracts from participants about using the model.

\begin{tabular}{|c|c|}
\hline Theme & Illustrative data extracts \\
\hline Reconciling a non-traditional approach & $\begin{array}{l}\text { "I think what makes it a little bit difficult is } \\
\text { making sure they are working together and not } \\
\text { relying on you completely" } \\
\text { "they just want answers" } \\
\text { "Sometimes it can be a little bit uncomfortable } \\
\text { at first because they're not used to it" } \\
\text { "It's uncomfortable at first..they expect to be } \\
\text { fixed..because that's what everyone else has } \\
\text { done with them" } \\
\text { "We call people participants...because we } \\
\text { participate in that journey" } \\
\text { "most of them (clients) are quite keen to say } \\
\text { what is wrong. It is the moving forward with how } \\
\text { they are going to tackle that that's more } \\
\text { challenging for them" } \\
\text { "I've had one person who when I wouldn't tell } \\
\text { her what to do, she said right, I don't want the } \\
\text { service anymore" } \\
\text { "it was about making sure it's not our agenda, } \\
\text { that we have to work...we don't have to get this } \\
\text { person into work" } \\
\text { "We don't have to make this person well...it's up } \\
\text { to the individual to do it" }\end{array}$ \\
\hline Promoting an holistic perspective & $\begin{array}{l}\text { "Remembering important details like the names } \\
\text { of children, so that's something that you can } \\
\text { mention next time and that sort of sticks with } \\
\text { the person" } \\
\text { "you're not saying right you want to } \\
\text { work...you're the smoker. It's the 'you're Julie } \\
\text { who has three kids and a dog named Polly"' } \\
\text { "you're looking at the person as a whole, not just } \\
\text { their health conditions or just their problems" } \\
\text { "at the end of the day they get to focus on what }\end{array}$ \\
\hline
\end{tabular}


Using a structured model to promote mental health.

\section{Purpose}

A Promoting Mental Health and Well-Being Working Model (Keeling and McQuarrie, 2014) was developed in response to recognition through teaching undergraduate nursing students, that interventions aimed at enhancing mental health and wellbeing are often hidden (Owens et al, 2010) or cloaked in traditional professional specific working interventions. The model was developed with the purpose of making the elements of mental health and well-being promotion visible and structuring them into a framework to aid working practice and personal development. The purpose of this paper is to evaluate the effectiveness from the participant perspective of using the model to enhance clients' mental health and well-being in community settings.

\section{Design/methodology/approach}

14 participants were interviewed within two focus groups. Five questions were posed to the participants structured around their experiences of using the model when working with clients in the community. The responses were recorded and transcribed and then categorised using a thematic analysis approach.

\section{Findings}

Three key themes were derived from the analysis in equal measure: "Reconciling a Non-traditional approach", "Promoting a holistic approach" and "Developing creativity and sense of empowerment to promote mental health and wellbeing". The findings suggest that using the model enabled participants to engage with clients in meaningful ways that in turn developed their self-confidence in helping clients develop creative strategies to promote their own mental health and wellbeing.

\section{Originality/value}

This paper shows that using a structured model to promote well-being and mental health has benefits in enhancing creativity, therapeutic relationships and knowledge base. Further research is needed in terms of the utility of the model from the client's perspective. . 


\section{Background}

The model was initially presented at an International conference (Keeling and McQuarrie,2010) and then used as a teaching tool to community workers in an attempt to bring together the elements of facilitating the promotion of mental health and wellbeing. Two focus groups were later used to elicit the experiences of those Participants $(n=14)$ in using the model when working with people in community settings.

Mental health and well-being promotion have increasingly gained recognition as important aspects of any caring activity. However, literature is often focused on mental health and well-being promotion as an adjunct or secondary consideration of treatment and professional led "fixing" which can lead to a reactive and reductionist approach to care (Johansson et al. 2009; Kelsey, 2017; Shah and Mountain, 2007). In developing the model, it was considered how mental health and well-being promotion could become the focus of caring activity with the intention that increased self-efficacy and behavioural change would become the catalyst for more long term behaviour change and health benefits (Cornwall et al, 2003). The model incorporates the concepts inherent within mental health and well-being promotion (Barry and Jenkins, 2007; Cattan and Tilford, 2006) but structures these concepts into a coherent framework for practitioners of any discipline to use (fig i). In enabling individuals to consider what is important to them and what they would like to change, it is argued that individuals can use initial success in these areas as a motivator to tackle other changes that may need to occur that initially may have been perceived as insurmountable. It is also acknowledged that mental health and well-being promotion may have very little obvious relationship to a diagnosis or presenting medical problem (Hermann, Saxena and Moodie, 2005). The model was designed on the initial premise that improved mental health and well-being may have a secondary effect of improving the presenting medical problem or health concern thus "flipping" the focus of caring activity to be person centred in its truest form (Cornwall et al., 2003; Keeling and McQuarrie, 2014).

The model consists of four key aspects or considerations that the practitioner can use as a guide to working in enabling individuals to discover their own goals and ways to well-being whether this be physical or emotional. Stage one of the model is concerned with collaborative working in identifying need: an important factor here is that the practitioner is a facilitator rather than instructive or a solver of problems. Literature indicates that individuals who feel involved in their own care and listened to have better health outcomes than those who are prescribed interventions based on professional deciphering of what the individual must need or want (Laurance et al. 2014). A truly inclusive approach to need identification is a key aspect or foundation of mental health and well-being promotion and gives indication to an individual from the outset that the locus of control lies internally. Deciphering what an individual needs is a fundamental aspect of traditional caring roles but can be a passive process for theclient due to concerns of workers regarding professional accountability and lack of training (Bee et al., 2005). (. The use of motivational interviewing techniques (Miller and Rollnick, 2002) may go some way to encouraging the client to be active in ascertaining need

Stage two of the model considers engagement with statutory and non-statutory services and requires the practitioner to have knowledge of what may be available to support an individual in meeting self-specified goals or in addressing self-perceived need. With the advent of and now established tele-health sector, individuals may find the use of self-referral processes and online 
material and support useful as opposed to face to face engagement (Robin et al. 2013; Balatsoukas et al. (2015) . However, this is itself requires consideration of the person's confidence and existing skills in order to predict whether this avenue may be useful. This can be elicited through using stage one of the model in getting to know the individual through a collaborative approach.

Stage three of the model is concerned with creativity in approach and is aimed at harnessing the pre-existing skills, interests and pastimes of an individual to best effect. Traditional interventions to address need may be useful in the short term but a person may have already established coping mechanisms that he uses to improve mental health and well-being when required (Cairns-Nagi and Bambra, 2013). An example here would be physical activity; the use of physical exercise has well known benefits to mental health and well-being: if an individual already engages in this activity thinking about how it can be used in a creative approach to address his need seems logical. The key aspect to this stage of the model is that the practitioner and individual are not constrained to using traditional or prescribed interventions. Mere engagement in a hobby or pasttime can have a profound effect on mental health and well-being and can act as an excellent motivator for facing future changes and challenges (Dickinson and Adams, 2014; Dieser and Christenson, 2016). The evidence base is growing for the use of many activities that have been traditionally viewed as meaningless hobbies or pastimes, as useful interventions in addressing health needs and concerns. Thus, the practitioner is required to develop skills in creativity in seeking out from the individual alternative pathways to reaching a desired state of well-being.

Stage four of the model prompts the practitioner and individual to consider conducive and constraining factors to implementation as an important consideration before embarking upon any individual's chosen strategy. An acknowledgement of what will help or hinder the potential progress in addressing a specific self-deciphered need is important in predisposing critical points of potential setback and perceived failure. Considering what is realistic and achievable in an individual's life is crucial in terms of maintaining confidence and self-esteem throughout any journey to enhanced well-being (Cox, 2011). Unrealistic expectations can be discussed and expectations managed if there is consideration of practical issues such as finances, accessibility and required skills. In terms of longevity of efficacy this is vital in ensuring that a person can be supported to pursue their goals without falling at the first hurdle. A discussion of how any constraining factors may be overcome and conducive factors enhanced can all aid in the planning process before activity is commenced. The practitioner in enhancing his own development must facilitate a discussion that not only identifies conducive and constraining factors to implementation, but has some suggestions in terms of how these might be manipulated to gain the best outcome for the client and to ensure that the service offered is meaningful (Cameron et al. 2018) .

\section{Figure $i$}

\section{Study Objective and Sample}

The purpose of the study was to evaluate the utility of the model in practice by eliciting the views of participants using the model in working with people in community practice settings in inner-city and suburban environments. The participants were placed within various community settings and accepted referrals from a range of professionals in addition to self-referrals through a dedicated Project website. All participants had undergone a training Programme structured around the principles of the model (fig i) and had been working in the community for 12 months as "well-being 
coaches". None of the participants had pre-existing professional affiliations although some did have experience working in health or social care previously in support roles.

\section{Method}

Two focus groups were held in order to elicit the views of the participants who had engaged in using the model. The use of focus groups is well established in the public health arena (O'Toole et al 2004; Hemingway et al, 2012) and are suited to collecting rich qualitative data from small groups who have engaged with a service or intervention (Breakwell and Millward, 1995). Further, focus groups were chosen as it enables participants to meet together, interact and share experiences regarding a common theme (Webb and Kevern, 2001). As the participants were all employed in a unique and new role, it was felt that a focus group would enhance the confidence of the participants in expressing their views and would provide the opportunity to discuss challenges together. The focus groups each lasted 60 minutes and comprised of the facilitator and seven Participants in each group. The focus group facilitator was conducted by one of the researchers, although the researcher did not provide any of the content of the training programme using the model. Written consent was gained from all participants prior to the focus groups. The subsequent discussions were audiotaped and then sent for independent transcribing prior to data analysis.

\section{Data Analysis}

The qualitative data emanating from the focus group discussions was transcribed and then analysed using a conventional content analysis approach (Hsieh and Shannon, 2005). Transcribed text from the focus groups was read several times by the two authors independently and coded according to reoccurring keywords/phrases and then these were grouped in themes culminating in a broad thematic analysis (Vaismoradi et al, 2013). Resultant broad themes deducted by the authors were then compared to check for parity and refinement.

\section{Key Findings}

Figure ii

Participants identified the challenges of working with the model and the usefulness of using the model in a collaborative and meaningful way both to themselves and the way they worked with individuals. Through thematic analysis of the focus group participant data, it became evident that using the model was initially challenging, but useful in enabling both the participant and the individuals they were working with, to ascertain their own needs and discover meaningful realistic routes to addressing them thus increasing self-efficacy.

Participant responses to the questions posed regarding use of the model fell into 3 main themes which were considered by the researchers as generally occurring with equal significance:

\section{Reconciling a Non-traditional approach}

Many comments made by participants focused on reconciling a non-traditional approach to need identification. Participants voiced that working in a collaborative way required time and effort on the practitioner part and was quite different from previous roles they may have been used to in the health sector, "especially coming from a health training background where it was kind of prescriptive 
and advice giving". Participants reported that self-development was important in reducing frustration and enabling the need to be discussed from the perspective of the client, "sit on your hands a little bit more and realise it's their goals, it's their choice not ours". Participants commented that "sometimes it can be a little bit uncomfortable at first because they are not used to it" in relation to discussing clients' thoughts and feelings about what they perceived their need to be. One participant commented, "I've had one person who when I wouldn't tell her what to do, she said right, I don't want the service anymore" indicating that working in a collaborative way can be a challenge to the traditional: not only confined to the practitioner but may also be experienced by the client. One participant commented that, "most of them (clients) are quite keen to say what is wrong. It is the moving forward with how they are going to tackle that that's more challenging for them". Participants made many positive comments about collaborative working, "some people get really motivated and enthused by it and run with it: the fact that they are setting their own goals" but balanced this with the work involved in enabling clients to understand the different approach to working, "I think what makes it a little bit difficult is making sure they are working together and not relying on you completely", "they just want answers". Participants discussed the collaborative approach and commented, "I think they take a little bit more responsibility", "I think once they realise it is up to them they like it a lot more as well".

Participants appeared to initially struggle with the concept of being an enabler or facilitator rather than trying to identify a client's need and then attempt to fix it. This was compounded by the expectation of the clients they were working with who appeared to have an expectation akin to this as this may have been what they had experienced from health workers in the past.

\section{Promoting a holistic approach}

Holism appeared to be a key theme derived from the participant comments. Participants voiced that they felt able to work with clients in collaboration and get to know them as individuals and this proved beneficial to identifying need. "Finding out what their interests are and developing a relationship" led to a "more personalised" approach in eliciting a client's needs. "Remembering important details like the names of children, so that's something that you can mention next time and that sort of sticks with the person". Participants spoke of the model enabling them to consider the wider determinants of health and well-being rather than just the presenting problem that the client was referred for help with, "you're looking at the person as a whole, not just their health conditions or just their problems". Participants spoke of how this way of working helped them to develop relationships with people and changed the narratives of the sessions to be more meaningful. Participants felt that this created a platform for negotiating creative ways for clients to start to work on the areas of their lives that they felt they would like to change.

\section{Developing creativity and sense of empowerment to promote mental health and wellbeing.}

Participants spoke of a feeling of developing confidence through working in a collaborative way and recognising that the client should take the lead in developing their own strategies for improving their own health and wellbeing. This also enabled a creative and bespoke approach to goal setting and action planning for attaining that goal. "I ask them what they want and together you come up with different ways to achieve it" 
Participants felt using the model enabled them to consider the conducive and constraining factors of different approaches and this developed their confidence to support clients on changing course if plans weren't working "we can be flexible with the tools we use...so if it isn't working then we just don't do it". Participants spoke of "creativity in approach" as extending beyond developing strategies to meet needs but to the way in which they delivered the whole service from initial meeting, "Because we're out in the community...that helps you be creative....we meet in a garden centre"

Participants spoke of moving from a place of being nervous around whether they would be effective in their work with clients, to a place of feeling inspired and innovative in their approaches to promoting mental health and wellbeing. "I think you can be more creative...as you're learning more yourself". Participants reported that working with the model encouraged a bespoke response to enabling clients to seek their own pathway to enhanced wellbeing "because it's not such a rigid structure...it allows you to be quite unique".

\section{Discussion}

The findings from the focus groups demonstrate the underpinning philosophy of the model in helping the participants develop strategies to engage people based on their individual needs and desires in relation to reconnecting to their lives and wellbeing.

There is hope that this choice of approach facilitates the development of creative thinking and thus creative practitioners (Gillam, 2013). Practitioners working within traditional service delivery models can be constrained in their ability to be creative. The philosophy of this model advocates a different approach to care which is based on the premise that when people feel better about themselves and fully involved in their care, outcomes will be more positive and longer lasting (Keyes, 2002; Prince et al, 2007).

The establishing of user led care and interventions can be a challenge for some practitioners, who are already enmeshed in a culture of providing the 'expert' role and advice. Indeed, Benner's (1982) model of development of nursing expertise could be applied to this scenario, when thinking about novice to expert development, traditionally people who are new to caring roles can sometimes feel less confident in their ability to 'let go' and let the client lead the care provided (Horsburgh and Ross, 2013). It is believed that this model can help facilitate the development of practitioners into confident and engaged partners in care much sooner than traditional working methods. Initially the participants reported needed a lot of support with insecurities due to being given a lot of leeway: this was different to what they had been used to, working in more traditional services with set ways of working.

The model lends itself towards an empowerment based approach, utilising a client's own interest and experiences to enrich the interaction between themselves and health providers. This moves away from a traditional behaviour change model, which focuses on 'righting' the client and their presenting problem/needs. Miller and Rollnick (2002) highlight this as a common, almost instinctive response from health professionals. Indeed, one participant stated that a client had told them that after many contacts with health services, 'this is the first time I feel that I've been listened to.' 
The participants highlighted that for some of them, being new to coming into this field was not an obstacle to engaging clients with this model. The self-efficacy of the participants and their development also followed a similar trajectory to their clients, creating a shared learning and experience which levelled the playing field, creating a more equal partnership of care.

The parallel training that was given to the participants in motivational interviewing techniques complimented the under pinning philosophy of the model. Participants felt that the skills they learned in encouraging clients to reflect and think about their own health needs enhanced their understanding of the purpose of the model. Engaging clients in an empathic, non-directive manner enabled the participants to be able to fully engage with the therapeutic process of promoting mental health and wellbeing. The way that the service was developed in terms of looking at working with people over a 12-month period helped facilitate the underpinning philosophy of the model - being able to develop the relationship and collaborate with people in the true sense. This was reliant on being able to focus on long term outcomes rather than quick solution focused short term outcomes.

\section{References}

Balatsoukas P., Kennedy, C.M., Buchan I., Powell J., Ainsworth J. (2015). The Role of Social Network Technologies in Online Health Promotion: A Narrative Review of Theoretical and Empirical Factors Influencing Intervention Effectiveness. J Med Internet Res, 2015, Vol.17 (6), p141.

Barry, M., \& Jenkins, R. (2007). Implementing mental health promotion. Elsevier.

Bee P., Brooks H., Fraser C. , \& Lovell K. (2015). Professional perspectives on service user and carer involvement in mental health care planning: A qualitative study. International Journal of Nursing Studies, 52(12), 1834-1845.

Benner, P. (1982). From novice to expert. American Journal of Nursing, 82(3), 402-407.

Breakwell, G. M., \& Millward, L. (1995). Basic Evaluation Methods: Analysing performance, practice and procedure. British Psychological Society.

Cairns-Nagi, J. M., \& Bambra, C. (2013). Defying the odds: A mixed-methods study of health resilience in deprived areas of England. Social Science and Medicine, 91, 229-237.

Cameron, L. J., Somerville, L. M., Naismith, C. E., Watterson, D. A., Maric, V., \& Lannin, N. (2018). A qualitative investigation into the patient-centered goal-setting practices of allied health clinicians working in rehabilitation. Clinical Rehabilitation 1, 2018.

Cattan, M., \& Tilford, S. (2006). Mental health promotion a lifespan approach. Maidenhead: Open University Press.

Cornwall, A., Lall, P., Kennedy, K., \& Owen, F. (2003). Putting partnership into practice: Participatory wellbeing assessment on a south London housing estate. Health Expectations, 6(1), 30-43. 
Cox, C. (2011). Reach Your Health Goal: Using Brief Motivational Interviewing for Goal-Setting. Physical \& Health Education Journal, 77(1), 25-27.

Dickinson, P., \& Adams, J. (2014). Resiliency and mental health and well-being among lesbian, gay and bisexual people. International Journal of Mental Health Promotion, 16(2), 1-9.

Dieser, R. B., \& Christenson, J. (2016). Integrating Positive Psychology, Behavioral Activation, and the Serious Leisure Perspective in Mental Health Counseling: a Case Report. International Journal of Applied Positive Psychology, 1(1-3), 57-68

Gillam, T. (2013). Creativity and mental health care. Mental Health Practice 16(9), 24-30.

Hemingway, S., White, J., Turner, J., Dewhirst, K., \& Smith, G. (2012). The medicine with respect project: A stakeholder focus group evaluation. Nurse Education in Practice, 12(6), 310-315.

Herrman, H., Saxena, S., Moodie, R., World Health Organization Department of Mental Health and,Substance Abuse, Victorian Health, P. F., University, o. M., et al. (2005). Promoting mental health : Concepts, emerging evidence, practice. Geneva: Geneva : World Health Organization.

Horsburgh, D., \& Ross, J. (2013). Care and compassion: The experiences of newly qualified staff nurses. Journal of Clinical Nursing, 22(7-8), 1124-1132.

Hsieh, H., \& Shannon, S. E. (2005). Three approaches to qualitative content analysis. Qualitative Health Research, 15(9), 1277-1288.

Johansson, H., Weinehall, L., \& Emmelin, M. (2009). "It depends on what you mean": A qualitative study of Swedish health professionals' views on health and health promotion. BMC Health Services Research, 9, 191.Keeling, J. L. \& McQuarrie, C. (2009). Promoting Mental Health in Practice: A Framework for Staff Development. Nordic Conference of Mental Health Nursing 2010. Finnish Nurses Association, Helsinki, Finland.

Keeling, J. L., \& McQuarrie, C. (2014). Promoting mental health and wellbeing in practice. Mental Health Practice (2014+), 17(5), 26.

Laurance, J., Henderson, S., Howitt, P., Matar, M., Al Kuwari, H., Edgman-Levitan, S., \& Darzi, A. (2014). Patient Engagement: Four Case Studies That Highlight The Potential For Improved Health Outcomes And Reduced Costs. Health Affairs, 33(9), 1627-34.

Kelsey, C. (2017). Promoting mental health in the workplace. Occupational Health \& Wellbeing, 69(10), 20-22.Keyes, C. (2002). The mental health continuum: From languishing to flourishing in life. Journal of Health and Social Behavior, 43(2), 207-22.

Miller, W., \& Rollnick, S. (2002). Motivational interviewing: Preparing people for change. $2^{\text {nd }}$ ed. London: Guildford Press 
O' Toole, M. S., Ohlsen, R. I., Taylor, T. M., Purvis, R., Walters, J., \& Pilowsky, L. S. (2004). Treating first episode psychosis - the service users' perspective: A focus group evaluation. Journal of Psychiatric and Mental Health Nursing, 11(3), 319-326.

Owens, C., Crone, D., Kilgour, L., \& El Ansari, W. (2010). The place and promotion of well-being in mental health services: A qualitative investigation. Journal of psychiatric and mental health nursing, 17(1), 1-8.

Kenter Robin, Warmerdam Lisanne, Brouwer-Dudokdewit Christine, Cuijpers Pim, \& Van Straten Annemieke. (2013). Guided online treatment in routine mental health care: An observational study on uptake, drop-out and effects. BMC Psychiatry, 13(1), 43.

Prince, M., Patel, V., Saxena, S., Maj, M., Maselko, J., Phillips, M. R., et al. (2007). No health without mental health. The Lancet, 370(9590), 859-877.

Shah P and Mountain D (2007). "The medical model is dead - long live the medical model". British Journal of Psychiatry, vol. 191 (5) pp.375-377.

Vaismoradi, M., Turunen, H., \& Bondas, T. (2013). Content analysis and thematic analysis: Implications for conducting a qualitative descriptive study. Nursing \& health sciences, 15(3), 398405.

Webb, C., \& Kevern, J. (2001). Focus groups as a research method: A critique of some aspects of their use in nursing research. Journal of Advanced Nursing, 33(6), 798-805. 